\title{
The effect of the chemical composition of maize plant lignin on the digestibility of maize stalk in the rumen of cattle
}

\author{
By NADIA F. CYMBALUK, A. J. GORDON AND \\ THE LATE T. S. NEUDOERFFER \\ Department of Nutrition, College of Biological Science, \\ University of Guelph, Guelph, Ontario \\ (Received I8 March I97 - Accepted 20 fune 1972)
}

\begin{abstract}
r. Digestibility of maize stalk from Troyer Reid $\left(T_{\gamma}\right)$ maize and its isogenic mutant $\left(b m_{1}\right)$ was studied by suspending nylon bags containing ground tissue in the rumen of a fistulated steer. The animal was given a grass hay-concentrate $(5: 3)$ diet or a maize silage-grass hayconcentrate $(4: 1: 3)$ diet.

2. The digestibility of the organic matter of the mutant maize stalk was greater than that of the normal maize stalk.

3. Adaptation of the rumen to maize silage increased the organic-matter digestibility of the maize stalk.

4. Lignin content was determined by two methods, namely organic matter iasoluble in $72 \%$ sulphuric acid (method of the Association of Official Agricultural Chemists, I960) (AOAC-lignin) and the organic matter lost from the ligno-cellulose complex (represented by acid-detergent fibre) by oxidation with potassium permanganate. The AOAC-lignin concentration was twice the permanganate-lignin concentration, but the amount of lignin estimated by both methods showed a significant negative relation to organic-matter digestibility. The AOAC-lignin concentration was greater in $T r$ than in $b m_{1}$ maize but the permanganate-lignin concentration in $T r$ was slightly lower than in $b m_{1}$.

5. There was an irregular relationship between the amount of lignin extractable with dimethylformamide (DMF) and digestibility of organic matter due to the solution of some of the DMF-lignin during digestion. The loss of lignin was greater from the mutant maize stalk tissue than from the parent maize stalk tissue.

6. The chemical composition of DMF-lignin determined by analysis showed a significant correlation between the syringealdehyde, $p$-hydroxybenzaldehyde and vanillin concentrations, and digestibility of organic matter.

7. Higher concentrations of both phenolic aldehydes and acids werc found in the less digestible $T r$ material than in the $b m_{1}$ stalk tissue.
\end{abstract}

Ruminants have a digestive system which enables them to utilize fibrous plant material. However, the efficiency of utilization of the carbohydrate and protein constituents of the plant varies and is related to, among other things, the degree of lignification (Van Soest, 1967). The lowering of the digestibility of plant organic matter by lignin is believed to be caused by the physical inaccessibility of cellulose to the microbial enzymes due to lignin encrustation of the microfibrils (Sullivan, 1962), the inability of microbial enzymes to degrade the lignin polymer (Van Soest, 1966) and the inhibition of enzymes by phenolic constituents of lignin (Patton \& Gieseker, I942).

The various studics which have been conducted to elucidate the relationship between lignin content and forage digestibility have been reviewed by Ely, Kane, Jacobson \& Moore (1953), Dehority, Johnson \& Conrad (1962) and Van Soest (1964). The studies of the effects of lignin on digestion have been based largely on values obtained 
by proximate analysis. These methods define lignin as a residue resistant to certain chemical treatments and furthermore these procedures do not permit the examination of the lignin itself. Thus, although it is well established that the lignin from different sources varies in composition (Stone, Blundell \& Tanner, I95I; Kuć \& Nelson, I964), few systematic studies of the relationship between lignin composition and digestibility of forages have been undertaken. Pigden \& Stone (1952) investigated the effect of digestion on the concentration of vanillin and syringealdehyde in lignin from Gramineae and Leguminosae. Bondi \& Meyer (1948) examined the effect of digestion on lignin methoxy content and they detected lignin breakdown products in sheep faeces. More recently, Allinson \& Osbourn (1970) showed that alteration in the u.v. absorption spectrum of lignin extracted with $0.5 \mathrm{M}$-sodium hydroxide was related to the digestibility of forages. Such studies relating digestibility of the plant to the composition, rather than to the amount of lignin present, have been limited. The introduction of a rapid quantitative gas-liquid chromatographic method for the determination of aromatic acids and aldehydes released from lignin on oxidation with nitrobenzene (Cymbaluk \& Neudoerffer, 1970) has made it possible to study the relationship of the chemical composition of lignin to forage digestibility. Such investigations have been further facilitated by the development of the brown midrib isogenic mutant $\left(b m_{1}\right)$ of Troyer Reid $(T r)$ maize (Gramineae) which was shown to differ only in its lignin composition from its parent (Gee, Nelson \& Kuć, 1968).

\section{EXPERIMENTAL}

Preparation of the maize stalk tissues. The $b m_{1}$ maize used in this study was introduced into the genotype of the inbred line $\operatorname{Tr}$ by six generations of back-crosses. It is isogenic with the inbred $T r$ except for the $b m_{1}$ locus and possibly some adjacent loci. The two inbred lines were planted on 19 May 1969 at the University of Guelph Crop Science Experimental Plots. The plants were harvested on 22 October 1969 just before the first killing frost. The maize plants were air-dried; the leaf tissue, tassels and ears of the maize were removed. The maize stalks were then dried in a forced-air oven at $37^{\circ}$ for $24 \mathrm{~h}$. The stalks were ground in a hammer-mill and then in a Wiley mill to pass through a $0.5 \mathrm{~mm}$ mesh screen.

Digestion of maize in vivo. The method of Neathery (1969) was used. Four nylon bags containing $b m_{1}(2 \circ \mathrm{g})$ and four nylon bags containing $\operatorname{Tr}(2 \circ \mathrm{g})$ maize stalk tissue were suspended simultaneously in the rumen of a $400 \mathrm{~kg}$ Hereford steer, through a fistula, I $h$ after feeding, and a bag of $\operatorname{Tr}$ and $b m_{1}$ maize tissue was removed $4.5,9$, $\mathrm{r} 8$ and $36 \mathrm{~h}$ later. The steer received a daily ration of either a grass hay-concentrate diet $(5 \mathrm{~kg}$ of grass $+3 \mathrm{~kg}$ concentrate) or a maize silage grass hay-concentrate $(4 \mathrm{~kg}$ silage $+\mathrm{r} \mathrm{kg}$ grass hay $+3 \mathrm{~kg}$ concentrate) diet. The concentrate contained a supplement which supplicd per $\mathrm{kg}$ concentrate: $5.5 \mathrm{~g}$ calcium, $5.0 \mathrm{~g}$ phosphorus, $2.9 \mathrm{~g}$ magnesium, $10 \mathrm{~g} \mathrm{NaCl}$, $100 \mathrm{mg}$ zinc, $210 \mathrm{mg}$ iron, $16 \mathrm{mg}$ copper, $50 \mathrm{mg}$ manganese, vitamin A (6 mg retinol), vitamin $\mathrm{D}(0.05 \mathrm{mg}$ cholecalciferol). Both diets supplied nutrients above the maintenance level (US) (National Research Council, 1963). The daily rations were given in two equal portions at 8.30 and 16.30 hours. $\mathrm{A}_{3}$-week 
period was allowed for the rumen flora to become adapted after the introduction of a new diet.

Treatment of the maize tissue after incubation. Bags with their contents were removed from the rumen, washed with distilled water and then freeze-dried. The bags and contents were extracted in a Soxhlet apparatus with acetone for $5 \mathrm{~h}$ and then with diethyl ether for $5 \mathrm{~h}$. They were then air-dried.

Some of the extracted maize stalk tissue $(2-3 \mathrm{~g})$ was retained for lignin determination by the method of the Association of Official Agricultural Chemists (1960) (AOAC-lignin). This lignin represents that part of the plant material which is insoluble in $72 \%$ sulphuric acid after pretreatment with ethanol-benzene, followed by treatment with $\mathrm{I} O \mathrm{~g}$ pepsin in I $10 . \mathrm{I} \mathrm{M}-\mathrm{HCl}$ and finally $5 \%$ sulphuric acid to remove carbohydrate and protein. It differs from other methods which also use $72 \%$ sulphuric acid, in the method of pretreatment of the plant material, an aspect of lignin determination studied by Whitehead \& Quicke (1964).

In some instances acid-detergent fibre (Van Soest, I963) and permanganate-lignin in acid-detergent fibre were determined (Van Soest $\&$ Wine, I968). Acid-detergent fibre is that part of the plant material which is insoluble in a boiling solution of $20 \mathrm{~g}$ cetyl trimethyl ammonium bromide/ $0.5 \mathrm{M}-\mathrm{H}_{2} \mathrm{SO}_{4}$. It represents primarily the lignocellulose fraction of the plant. When the acid-detergent fibre is oxidized by potassium permanganate, the resultant loss in weight is thought to represent the lignin content of the material (permanganate-lignin: Van Soest $\&$ Wine, 1968).

The remainder of the incubated sample was extracted with redistilled dimethylformamide (100 $\mathrm{ml} / \mathrm{g}$ ) to obtain dimethylformamide-lignin (DMF-lignin) according to the method of Gee et al. (1968).

Carbon, hydrogen and nitrogen analysis of DMF-lignin. Analysis for carbon, hydrogen and nitrogen in the DMF-lignin samples was carried out on a Hewlett-Packard Model ${ }^{8} 5$ Carbon, Hydrogen, Nitrogen Analyzer. Samples of each DMF-lignin $(0.63 \pm 0.06 \mathrm{mg})$ were oxidized using Model $18_{5}$ Oxidizing Catalyst (HewlettPackard Co., Avondale, Pennsylvania, USA). The temperatures of the oxidation furnace, reduction furnace, column oven and oven shell were maintained at ro6o, 485,90 and $60^{\circ}$ respectively, throughout all the analyses. The flow rate of helium gas was $100 \mathrm{ml} / \mathrm{min}$. Analysis of lignin from material digested for $36 \mathrm{~h}$ was not determined.

Alkaline nitrobenzene oxidation of DMF-lignin. To ascertain the alteration in the chemical composition of lignin by digestive processes, the concentrations of the oxidation products of DMF-lignin samples were determined according to the method of Cymbaluk \& Neudoerffer (1970). All the solvents used were redistilled before use.

Experimental design and statistical analysis. The experiment consisted of a $2 \times 2 \times 4$ factorial arrangement in a randomized complete block design, with each treatment having two replicates. The variables were type of maize [mutant $\left(b m_{1}\right)$ and normal $(T r)$, dietary regimen (grass hay-concentrate and maize silage-grass hay-concentrate) and length of incubation period $(4 \cdot 5,9,18$ and $36 \mathrm{~h})$. All the results obtained from the digestion studies were subjected to analysis of variance (Steel \& 'Torrie, r960) and regression analyses were made between organic-matter digestibility and the 
following chemical variables: AOAC-lignin, permanganate-lignin in acid-detergent fibre, and DMF-lignin (Snedecor \& Cochran, 1968). Paired $t$ test analysis was applied to determine the significance of the difference between the contents of DMFlignins from unincubated $T r$ and $b m_{1}$ maize tissue. All tests of significance were made at the $5 \%$ probability level.

\section{RESULTS}

Analysis of the composition of isogenic mutant $\left(\mathrm{bm}_{1}\right)$ and its parent $(\mathrm{Tr})$ maize. The leaves from $b m_{1}$ maize plants exhibited the typical brown midrib. The number and size of ears, height and total weight of plant were similar for the two types of maize plant. Both plants had reached senescence at harvesting. The results of the AOAC-lignin, permanganate-lignin and DMF-lignin, elemental and aromatic acid and aldehyde composition of the DMF-lignin are given in Table $\mathrm{r}$. The AOAClignin content of the $b m_{1}$ plant was $89 \%$ of that of the parent plant, and this observation was similar to results obtained by Kuć \& Nelson (1964) who showed that, when determined by a modified method of Ross \& Potter (1930), the lignin content of 96-d-old $b m_{1}$ plants was $86 \%$ of the parent plant. This modified method of Ross \& Potter (1930) used $37 \%$ formaldehyde in the pretreatment stage without the use of pepsin- $\mathrm{HCl}$ to remove carbohydrate and protein. However, the lignin contents of mixed stalk and leaf tissue obtained by Kuć \& Nelson (1964) with $T r$ and $b m_{1}$ maize were $6-8 \%$ higher than the content of lignin from maize stalk tissue observed in this study. The lignin content of maize stalk alone should be greater than that of a mixture of leaf and stalk material, since leaf tissue is likely to have a lower lignin content than stem tissue.

Permanganate-lignin concentration did not follow the trend of lignin concentration determined by the sulphuric acid method (AOAC-lignin) since, by the permanganate method, the lignin concentration of the $b m_{1}$ mutant was slightly greater than that of the normal maize, although the difference was not significant. Also, lignin concentrations determined by the permanganate method were considerably lower than the AOAC-lignin contents.

As with AOAC-lignin, the DMF-lignin content of the $b m_{1}$ maize stalk is less than the DMF-lignin content of the Tr maize tissue. Previous analysis of the DMF-lignin in maize stalk has been reported by Gec et al. (1968) but these workers recovered only $3 \mathrm{~g} / \mathrm{kg}$ DMF-lignin from the total plant. The DMF-lignin yields obtained here were considerably greater, $10.6 \mathrm{~g} / \mathrm{kg}$ of the total maize stalk dry matter from $b m_{1}$ and $16 \cdot 2 \mathrm{~g} / \mathrm{kg}$ of the total maize stalk dry matter from $\operatorname{Tr}$. Thus, although these determinations show the lignin content of the two varieties of maize to be different, the differences were dependent on the method used for the lignin analysis and possibly where the maize material analysed was grown.

In addition to differences in the amount of DMF-lignin from the two varieties of maize, the elemental analysis showed that the two lignins were different. The carbon and hydrogen contents of normal maize DMF-lignin were higher than in mutant maize DMF-lignin, although the nitrogen content was lower. The nitrogen 
Table $\mathrm{I}$. Chemical composition of mutant $\left(\mathrm{bm}_{1}\right)$ and normal $(\mathrm{Tr})$ maize stalk and the compositions of their respective DMF-lignins

(Mean values of duplicate detcrminations)

\begin{tabular}{|c|c|c|c|c|c|c|c|}
\hline \multirow[b]{3}{*}{$\begin{array}{l}\text { Maize } \\
\text { stalk }\end{array}$} & \multirow[b]{3}{*}{$\begin{array}{l}\text { AOAC-lignin } \\
(\mathrm{g} / \mathrm{kg} \mathrm{DM})\end{array}$} & \multicolumn{2}{|c|}{ Acid-detergent } & \multirow{3}{*}{$\begin{array}{l}\text { Concentration } \\
\text { of } \\
\text { DMF-lignin } \\
(\mathrm{g} / \mathrm{kg} D M)\end{array}$} & \multirow{2}{*}{\multicolumn{3}{|c|}{ Content in DMF-lignin $(\mathrm{g} / \mathrm{kg})$}} \\
\hline & & Fibre $P$ & $\begin{array}{l}\text { Permanganate- } \\
\text { lignin* }\end{array}$ & & & & \\
\hline & & $(\mathrm{g} / \mathrm{kg}$ & & & \multirow{2}{*}{$\begin{array}{l}\text { Carbon } \\
566\end{array}$} & \multirow{2}{*}{$\begin{array}{l}\text { Hydrogen } \\
\qquad 52\end{array}$} & \multirow{2}{*}{$\begin{array}{c}\text { Nitroger } \\
\text { I4 }\end{array}$} \\
\hline $\begin{array}{l}T_{\gamma} \\
\text { normal }\end{array}$ & 165 & 409 & 74 & I6 & & & \\
\hline \multirow{3}{*}{$\begin{array}{l}b m_{1} \\
\text { mutant }\end{array}$} & I 46 & $43 \mathrm{I}$ & 76 & II & 513 & 50 & 17 \\
\hline & \multicolumn{7}{|c|}{ Concentration of aromatic oxidation products in DMF-lignin $(\mathrm{g} / \mathrm{kg})$} \\
\hline & $p$-Hydroxyben & aldehyde & Vanillin & Syringealdehyd & \multicolumn{2}{|c|}{ le $\begin{array}{c}p \text {-Coumaric } \\
\text { acid }\end{array}$} & $\begin{array}{l}\text { Ferulic } \\
\text { acid }\end{array}$ \\
\hline $\begin{array}{l}T_{r} \\
\text { normal }\end{array}$ & 76.6 & & $8 I^{\circ} \circ$ & $128 \cdot 5$ & \multicolumn{2}{|c|}{$7 \cdot 8$} & $23 \cdot 6$ \\
\hline $\begin{array}{l}b m_{1} \\
\text { mutant }\end{array}$ & $36 \cdot 5$ & & $5^{6 \cdot 1}$ & $55 \cdot 4$ & \multicolumn{2}{|c|}{$5 \cdot 5$} & $19 \cdot 9$ \\
\hline
\end{tabular}

DMF-lignin, lignin soluble in dimethylformamide; AOAC-lignin, lignin estimated by the method of the Association of Official Agricultural Chemists (I,60); DM, dry matter.

* Determined by the method of Van Soest \& Wine (1968).

contents of both DMF-lignins were higher than values obtained by Gee et al. (I968). This may have been due to protein contaminants (Thomas \& Armstrong, 1949) or to nitrogen-containing compounds forming part of the lignin polymer (Bondi \& Meyer, 1948).

Analyses of the alkaline nitrobenzene oxidation products of the two DMF-lignins also revealed a difference between the lignins of the mutant and normal maize stalk material. The concentrations of oxidation products in DMF-lignin from normal plants were significantly higher than the oxidation products of the DMF-lignin from mutant plants. There was a notable difference between the concentrations of aromatic aldehydes, especially syringealdehyde, in the two DMF-lignins. The concentration of syringealdehyde in the $\operatorname{Tr}$ maize stalk tissue was almost 2.5 times the syringealdehyde concentration in the $b m_{1}$ maize stalk tissue.

Effect of in vivo digestion of $\mathrm{bm}_{1}$ mutant and $\mathrm{Tr}$ normal maize stalk on the composition of their DMF-lignins. The results of the in vivo digestion experiments show that the amount of organic matter dissolved with the maize stalk material from $T r$ plant on both dietary regimens was lower than that of the $b m_{1}$ maize stalk material (Fig. I). However, on the maize-silage diet, both stalk materials were digested at a faster rate than on the hay-concentrate diet for the first $4^{\cdot 5-9} \cdot 9^{\circ} \mathrm{h}$ of incubation. After $4 \cdot 5 \cdot 9^{\circ} \mathrm{O}$ the rate of organic-matter digestion for $T r$ and $b m_{1}$ decreased on the maize-silage diet but increased on the hay-concentrate diet. After $9.0 \mathrm{~h}$ the lines in Fig. I are essentially rectilinear and parallel, indicating that the rates of digestion of $T r$ and $b m_{1}$ maize on both diets were the same, although at any given time the maize-silage diet 


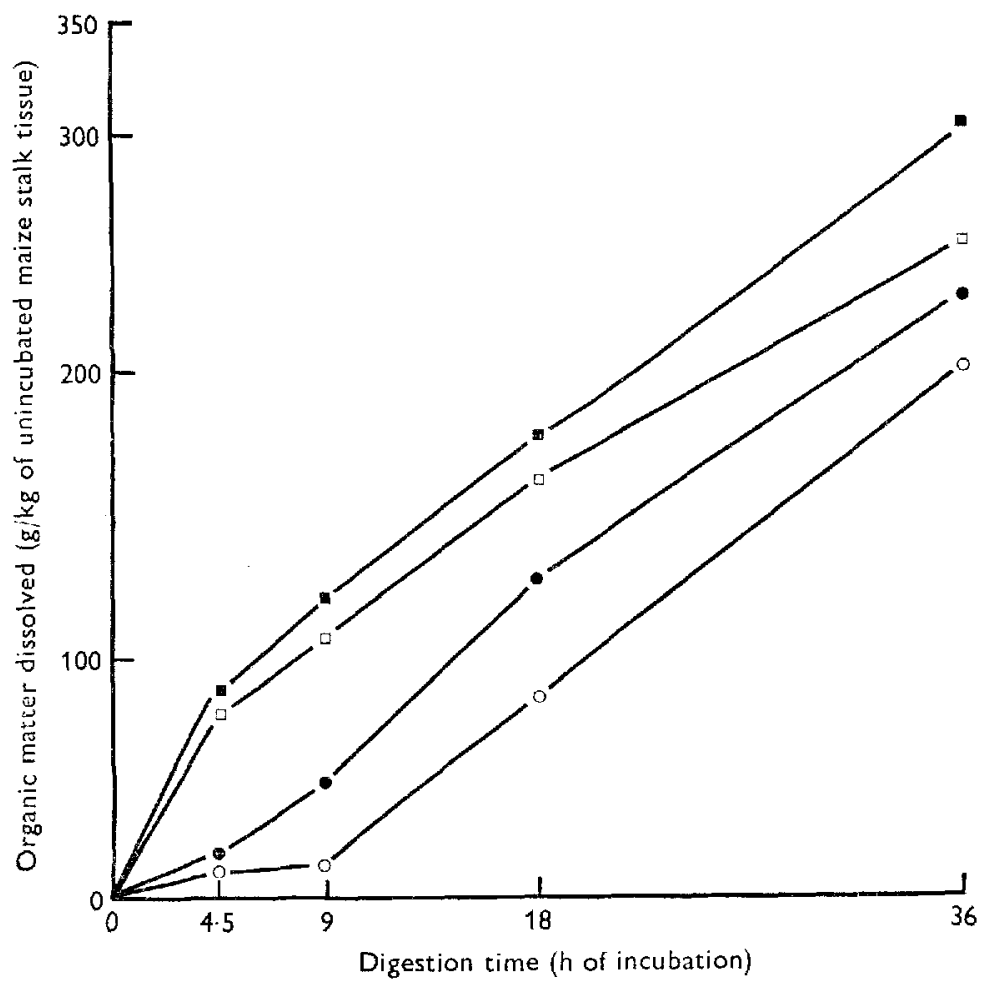

Fig. I. Loss of organic matter from $b m_{1}$ mutant and $T r$ normal maize stalk tissues, incubated in the rumen of a steer given either a grass hay-concentrate $(5: 3)$ diet or a maize silage-grass hay-concentrate $(4: 1: 3)$ diet. $-6, b m_{1}$, hay diet; $\mathrm{O}-\mathrm{O}, \operatorname{Tr}$, hay diet; $\mathbf{E}-\mathbf{E}, b m_{1}$, maize-silage diet; $\square-\square, T r$, maize-silage diet.

resulted in a higher digestion of the $T r$ and $b m_{1}$ maize tissue. There was no statistically significant difference between replicate experiments but the digestion of the maize stalk organic matter was significantly affected by type of maize, dietary regimen and length of incubation.

$\mathrm{Up}$ to $9 \mathrm{~h}$ the concentration of AOAC-lignin increased as dissolution of associated plant material progressed (Fig. 2). Even up to $3^{6} \mathrm{~h}$ a significant negative correlation $(r=-0.69)$ was found between AOAC-lignin content and the degree of maize stalk digestion. The relationship between permanganate-lignin and digestion was determined with several samples. Here, also, there was a significant negative correlation $(r=-0.95)$ between lignin content and degree of maize stalk digestion.

The amounts of lignin from $T r$ and $b m_{1}$ maize stalk tissue, which were extractable with DMF after incubation in the rumen of animals given both diets, are shown in Fig. 3. For all the treatments there was a marked decrease in the amount of lignin extractable with DMF after the first $4.5 \mathrm{~h}$ of incubation. In the rumen of the animal given the grass hay-concentrate diet, the $T r$ and $b m_{1}$ tissues showed an increase in the amount of lignin extractable with DMF during the second $4.5 \mathrm{~h}$ period of incubation and this reached a maximum at $18 \mathrm{~h}$ and declined slightly after that. In contrast, for the maize-silage diet, the amount of lignin extractable with DMF from 


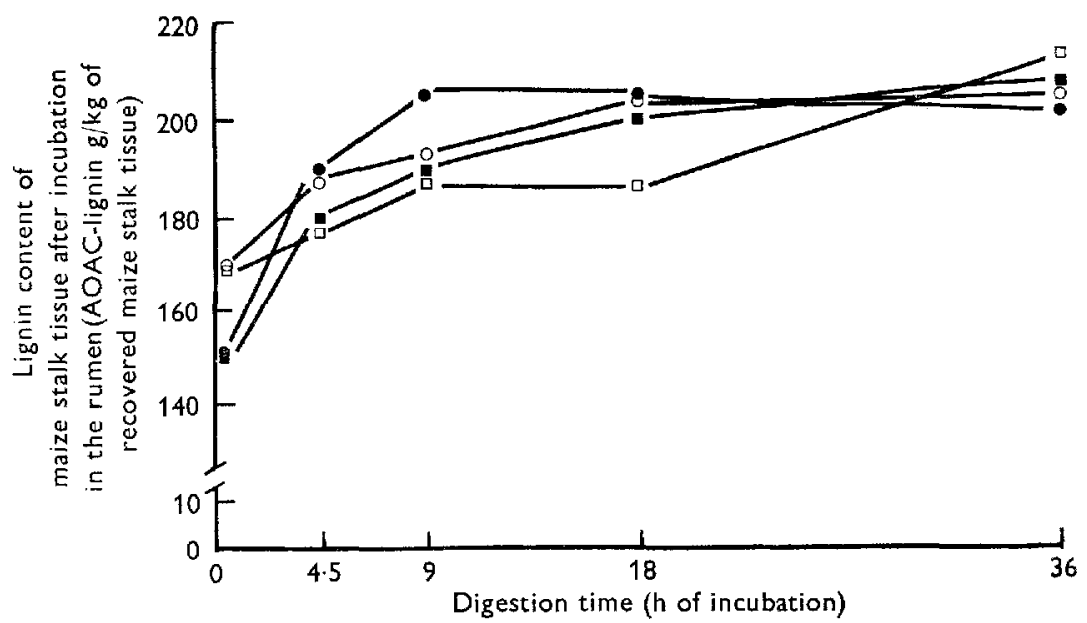

Fig. 2. Lignin content, determined by the method of the Association of Official Agricultural Chemists (1960) (AOAC-lignin), of $T r$ and $b m_{1}$, maize stalk tissues after incubation in the rumen of a steer given either a grass hay-concentrate $(5: 3)$ diet or a maize silage-grass haym concentrate $(4: 1: 3)$ diet. $-b m_{1}$, hay diet; $\bigcirc-O$, Tr, hay diet; $\mathbf{B}-b m_{1}$, maizesilage diet; $\Pi-[1, T r$, maize-silage diet.

the $b m_{1}$ maize tissue continued to decline after $4 \cdot 5 \mathrm{~h}$, although this was at a slower rate than before, until a minimum amount of DMF-lignin was extractable after i $8 \mathrm{~h}$, after which the amount increased. With the same diet, the $\operatorname{Tr}$ maize tissue showed a linear increase in the DMF-extractable lignin after $4.5 \mathrm{~h}$; so after $3^{6 \mathrm{~h}}$ the amount of lignin extracted by DMF from the $T r$ maize was about the same as that extracted from $\operatorname{Tr}$ and $b m_{1}$ maize tissue for the grass hay-concentrate diet but twice that of its $b m_{1}$ mutant for the maize-silage diet.

From the results shown in Figs $x$ and 3 it may be concluded that there was a negative relationship between the amount of lignin extractable with DMF and the proportion of organic matter digested. For both $T r$ and $b m_{1}$ maize tissues, digestion was greater with the maize silage-concentrate diet than with the grass hay-concentrate diet; but with the former diet, there was a lower amount of lignin extractable with DMF. Similarly, with both diets the $b m_{1}$ maize tissues had a higher digestibility but a lower amount of DMF-lignin than the $T r$ maize tissue. However, this relationship was only apparent during the first $4.5 \mathrm{~h}$. Although organic matter was dissolved at a constant rate from 4.5 to $3^{6} \mathrm{~h}$, the amount of lignin extractable with DMF tended to rise slightly in this period (except for the $b m_{1}$ maize-silage treatment, when a slight decrease occurred until $\mathbf{r} 8 \mathrm{~h}$ ) instead of declining as would be expected if the negative relationship existed. The loss of DMF-lignin during the first $4.5 \mathrm{~h}$ of incubation was probably due to solution of DMF-soluble lignin by digestive processes.

Carbon, hydrogen and nitrogen contents of each sample of DMF-lignin were assessed to determine changes brought about by digestion (Fig. 4). The carbon content of the DMF-lignin from unincubated $T r$ material was greater than that of DMF-lignin from unincubated $b m_{1}$ material and up to $9 \mathrm{~h}$ of suspension this pattern was maintained in the recoverable DMF-lignin. After the $9 \mathrm{~h}$ period of digestion, 


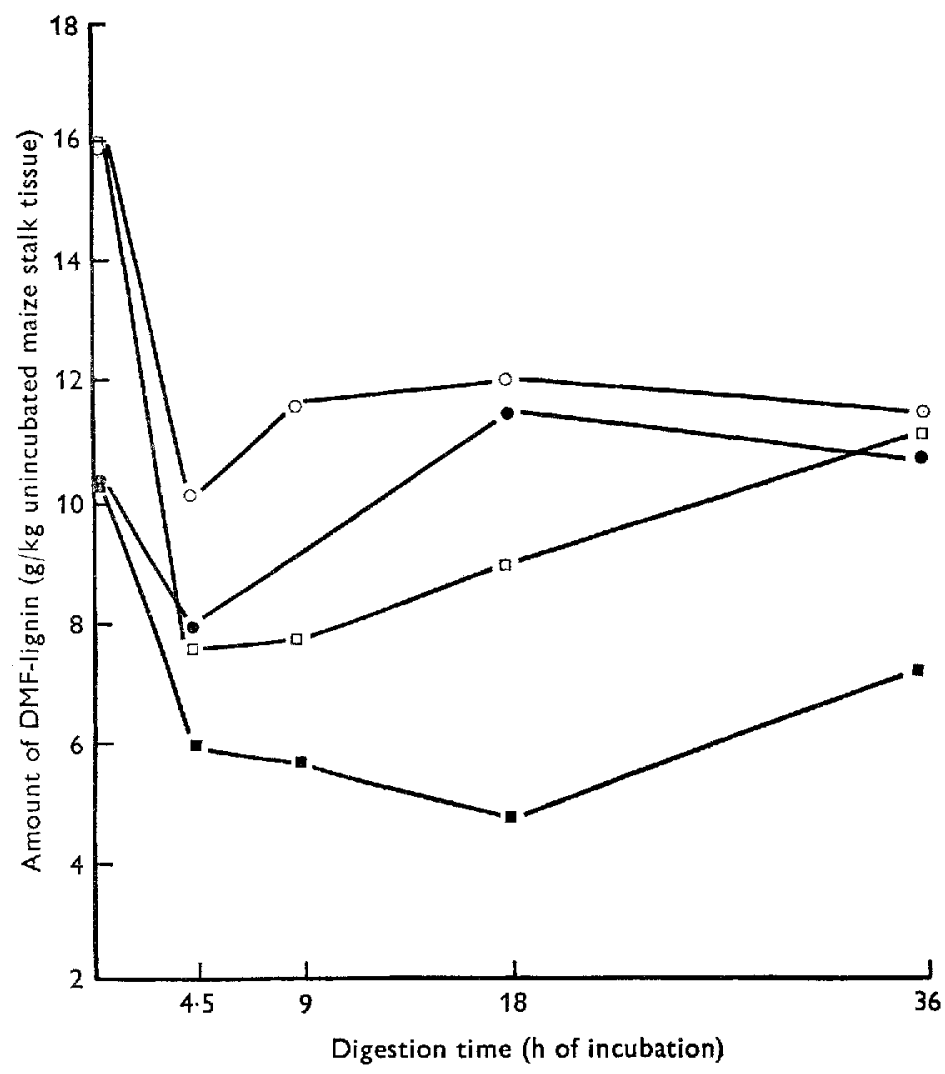

Fig. 3. Amount of lignin extractable with dimethylformamide (DMF-lignin) from $\operatorname{Tr}$ and $b m_{1}$ maize stall tissues after incubation in the rumen of a steer given either a grass hayconcentrate $(5: 3)$ diet or a maize silage-grass hay-concentrate $(4: 1 ; 3)$ diet. $-\mathbf{0}, \mathrm{bm}_{1}$, hay diet; $\bigcirc-O, \operatorname{Tr}$, hay diet; $-\mathbf{D}, b m_{1}$, maize-silage diet; $\square-\square, T r$, maize-silage diet.

the DMF-lignin from material digested in the rumen adapted to maize stalk utilization had a lower carbon concentration than the DMF-lignin from material digested in the rumen of the animal when it was given only a hay-concentrate diet. The effect of maize digestion on the hydrogen concentration of DMF-lignin followed a pattern qualitatively similar to that for carbon (Fig. 4). After $4.5 \mathrm{~h}$, nitrogen content of the DMF-lignin from $b m_{1}$ maize stalk digested in the maize silage-adapted rumen was higher than that of the other three samples (Fig. 4). The difference between the pattern of change in nitrogen concentration on the one hand and the pattern of change of hydrogen and carbon on the other hand might be pertinent to the nature of the association of nitrogen in the lignin polymer (Thomas \& Armstrong, 1949).

The oxidation products of all DMF-lignins were analysed to confirm that alterations had occurred in the DMF-lignin during digestive processes. The concentrations of aromatic aldehydes in recovered undigested maize stalk tissue are given in Fig. 5. The concentrations of aromatic aldehydes decreased within the first $4^{\circ} 5^{\mathrm{h}}$ of incubation in the rumen, then increased during the subsequent $4^{*} 5 \mathrm{~h}$. After $9 \mathrm{~h}$ of incubation 


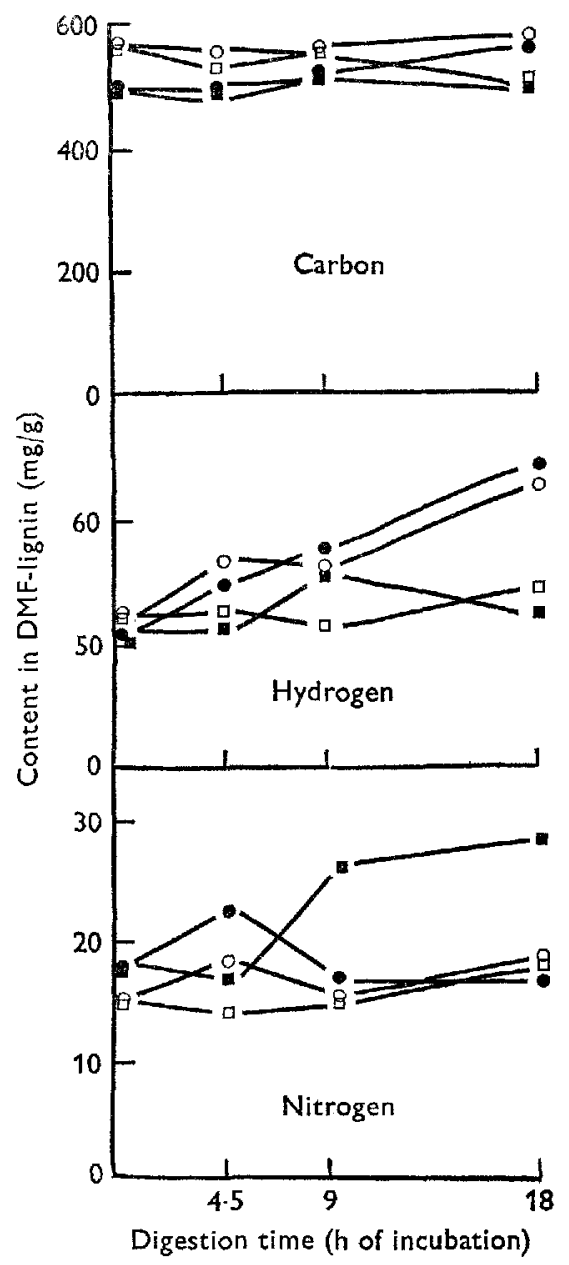

Fig. 4. Contents of carbon, hydrogen and nitrogen in the lignin extractable with dimethylformamide (DMF-lignin) from $T r$ and $b m_{1}$ maize stalk tissues after incubation in the rumen of a steer given either a grass hay-concentrate $(5: 3)$ diet; or a maize silage-grass hayconcentrate $(4: 1: 3)$ diet.,$- b m_{1}$, hay diet; $\bigcirc-O, T r$, hay diet; $-\mathbf{D}, b m_{1}$, maize-silage diet; $\square-\square, T r$, maize-silage diet.

the concentrations of aromatic aldehydes showed only slight variation. The initial differences in aromatic aldehyde concentrations between maize types was maintained after digestion. The changes in the aldehyde concentration (Fig. 5) rendered by incubation in vivo were significant and were related to the type of maize and the length of the incubation period.

The changes in the concentrations of aromatic acids are also shown in Fig. 5. In contrast to the concentrations of aromatic aldehydes, the aromatic acids were present in low concentrations during the first $9^{-1} 8 \mathrm{~h}$. After $\mathrm{i} 8 \mathrm{~h}$ the concentration of $p$-coumaric acid increased rapidly in both the $T r$ and $b m_{1}$ maize samples suspended in the rumen of the animal given the maize-silage diet. In contrast to this, in the rumen of the animal given the grass hay-concentrate diet, the concentration of $p$-coumaric 


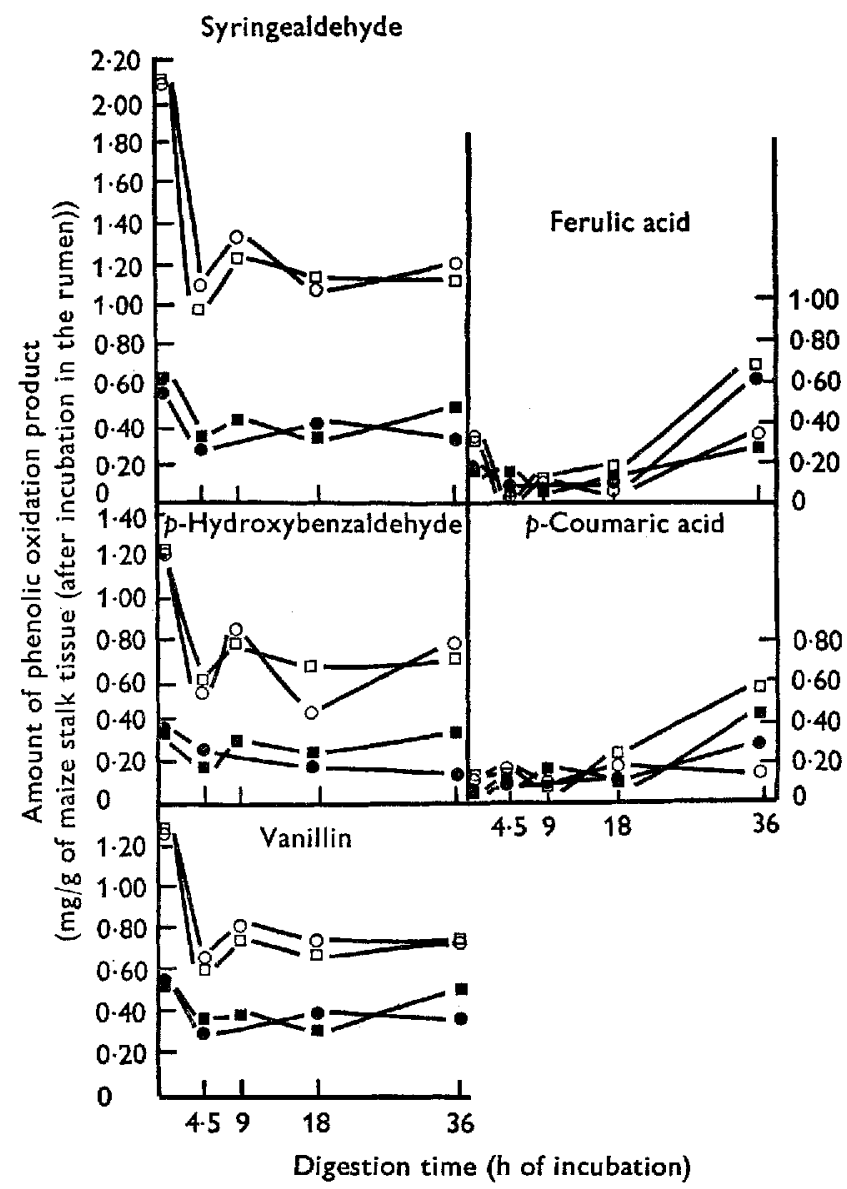

Fig. 5. Concentration of phenolic nitrobenzene oxidation products (syringealdehyde, $p$ hydroxybenzaldehyde, vanillin, $p$-coumaric acid, ferulic acid) from $T r$ and $b m_{1}$ maize stalk tissue after incubation in the rumen of a steer given either a grass hay-concentrate $(5: 3)$ diet or a maize silage-grass hay-concentrate $(4: \mathrm{r}: 3)$ diet. $-0, b m_{1}$, hay diet; $\bigcirc-O, T r$, hay diet; - $b m_{1}$, maize-silage diet; $\square-\square, T r$, maize-silage diet.

acid in the mutant maize sample increased only slightly, whereas for the normal maize sample the concentration of this acid decreased slightly and was lower than that of the mutant.

After I $8 \mathrm{~h}$ the concentration of ferulic acid in both the $T r$ and $b m_{1}$ maize samples increased for both diets. As with $p$-coumaric acid, the greatest increase in ferulic acid occurred in the $\operatorname{Tr}$ maize sample with the maize-silage diet but unlike $p$-coumaric acid the concentration of ferulic acid in the $b m_{1}$ maize sample for this diet showed only a slight increase. A further difference compared with $p$-coumaric acid occurred in the samples suspended in the rumen of the animal given the grass hay-concentrate diet where the increase in concentration of ferulic acid in the mutant maize sample was much greater than the corresponding increase for $p$-coumaric acid and was equal to the increase for the $\operatorname{Tr}$ maize sample suspended in the rumen of the animal given the maize-silage diet. 


\section{DISCUSSION}

Although the AOAC-lignin and permanganate-lignin content of plant material remaining after digestion is significantly correlated with the digestibility of plant organic matter, little can be said about the reason for the correlation, because the lignin obtained is altered or destroyed. Although the lignin extracted with organic solvents constitutes only a small proportion of total lignin, it was probably unaltered. However, substantial proportions of the organic-solvent-extractable lignin were lost during the early stages of digestion.

The results of the measurements of the content of carbon, hydrogen or nitrogen were consistent with changes in lignin during digestion, but the adaptation of rumen micro-organisms seems to play an important part.

The decrease in the concentration of the aromatic aldehydes during the first $4.5 \mathrm{~h}$ of incubation and the increase in the concentration of the aromatic acids after $18 \mathrm{~h}$ of incubation in the rumen may have been the results of changes in the composition of DMF-lignin only. It is possible that the high content of syringealdehyde in the $T r$ maize is related to the reduced digestibility of the plant. Syringealdehyde contains two methoxyl groups/molecule, whereas vanillin and $p$-hydroxybenzaldehyde contain one and none respectively. As plants age, the methoxyl content of their lignin increases and their digestibility declines (Quicke \& Bentley, 1959), and it is possible that the spatial configuration of syringealdehyde in the lignin may interfere with the decomposition of cell wall components by micro-organisms.

The recognition of significant correlations between chemical constituents of lignin and digestibility may facilitate systematic plant breeding programmes even though such studies would at present be based on information on a small fraction of total lignin in plants.

The authors thank Drs B. Hunter and L. Kannenberg of the Department of Crop Science for providing the two types of maize plant used in this study. The financial support of the Canada Department of Agriculture and the Ontario Department of Agriculture and Food is gratefully acknowledged.

\section{REFERENCES}

Allinson, D. W. \& Osbourn, D. F. (1970). Y. agric. Sci., Camb. 74, 23.

Association of Official Agricultural Chemists (1960). Methods of Analysis p. 91. Washington, DC: Association of Official Agricultural Chemists.

Bondi, A. \& Meyer, H. (1948). Biochem. F. 43, 248.

Cymbaluk, N. F. \& Neudoerffer, T. S. (1970). F. Chromat. 5I, 167.

Dehority, B. A., Johnson, R. R. \& Conrad, H. R. (r962). F. Dairy Sci. 45, 508.

Ely, R. E., Kane, E. A., Jacobson, W. C. \& Moore, L. A. (1953), F. Dairy Sci. 36, 346.

Gee, M. S., Nelson, O. E. \& Kuc, J. (1968). Archs Biochem. Biophys, 123, 403.

Kuć, J. \& Nelson, O. E. (1964). Archs Biochem. Biophys. 105, 103.

National Research Council (r963). Publs natn. Res. Coun., Wash. no. I 137, 3 rd ed.

Neathery, M. W. (1969). F. Dairy Sci. 52, 74.

Patton, A. R. \& Gieseker, I. (r942). F. Anim. Sci. I, 22.

Pigden, W. J. \& Stone, J. E. (I952). Sci. Agric. 32, 502.

Quicke, G. V. \& Bentley, O. G. (1959). F. Anim. Sci. 18, 365 . 
Ross, J. H. \& Potter, J. C. (1930). Puip Pap. Mag. Can. 24, 549.

Snedecor, G. W. \& Cochran, W. G. (1968). Statistical Methods 6th ed. Ames, Iowa: Iowa State University Press.

Steel, R. G. D. \& Torrie, J. H. (1960). Principles and Procedures of Statistics. New York: McGraw-Hill. Stone, J. E., Blundell, M. J. \& Tanner, K. G. (195 I). Can. F. Chem. 29, 734.

Sullivan, J. T. ( 1962). Agron. $\mathcal{~} .54,5$ I 1 .

Thomas, B. \& Armstrong, D. G. (1949). I. agric. Sci., Camb. 39, 335.

Van Soest, P. J. (1963). 7. Ass. off. agric. Chem. 46, 829.

Van Soest, P. J. (1964). F. Anim. Sci. 23, 838 .

Van Soest, P. J. (1966). F. Ass. off. analyt. Chem. 49, 546.

Van Soest, P. J. (1967). F. Anim. Sci. 26, 1 19.

Van Soest, P. J. \& Wine, R. H. (1 968). F. Ass, off. analyt. Chem. 5r, 780.

Whitehead, D. L. \& Quicke, G. V. (1964). J. Sci. Fd Agric. 15, 4I 7. 